\title{
FAKTOR-FAKTOR YANG MEMPENGARUHI KEPUASAN PELANGGAN PADA JASA TRANSPORTASI PERUSAHAAN OTOBUS BUDIMAN JURUSAN TASIKMALAYA-CIKARANG
}

(Survey Pada Penumpang Bus Budiman Jurusan Tasikmalaya-Cikarang)

\author{
Rismawati \\ Ina Ratnasari
}

\begin{abstract}
Rismawati
S1 Manajemen, Fakultas Ekonomi, Universitas Singaperbangsa Karawang rismawatii536@gmail.com, ina.ratnasari@fe.unsika.ac.id
\end{abstract}

\begin{abstract}
ABSTRAK
Tujuan dari penelitian ini adalah untuk menguji dan menganalisis faktor-faktor apa saja yang mempengaruhi kepuasan pelanggan pada jasa transportasi perusahaan otobus budiman jurusan tasikmalaya-cikarang. Faktor-faktor yang akan dianalisis dalam penelitian ini adalah faktor biaya perjalanan, faktor waktu perjalanan, faktor waktu tunggu, faktor aksesibilitas, faktor kesesuaian, faktor keamanan/keselamatan. Hasil penelitian yang diperoleh dari uji analisis faktor menunjukkan bahwa diperoleh 3 faktor yang berpengaruh paling dominan terhadap kepuasan pelanggan dalam memilih angkutan jasa transportasi umum bus budiman jurusan tasikmalaya-cikarang. faktor-faktor tersebut adalah : faktor biaya perjalanan 36,59\%, faktor waktu perjalanan $12,86 \%$, faktor keamanan/keselamatan $7,422 \%$. Faktor yang paling dominan mempengaruhi kepuasan pelanggan adalah faktor biaya perjalanan, faktor waktu perjalanan dan faktor keamanan/keselamatan. sedangkan sisanya dipengaruhi oleh faktor lain yang tidak diteliti.
\end{abstract}

Kata Kunci : Analisis Faktor, Jasa Transportasi Umum, kepuasan Pelanggan.

\begin{abstract}
The purpose of this study is to examine and analyze the factors that affect customer satisfaction in the transportation services of the Budiman bus company, majoring in Tasikmalaya-Cikarang. The factors that will be analyzed in this study are the travel cost factor, the travel time factor, the waiting time factor, the accessibility factor, the suitability factor, the security/safety factor. The data were obtained from
\end{abstract}


distributing questionnaires to 277 respondents who used the Budiman bus majoring in Tasikmalaya-Cikarang. The data analysis technique used is the scale range technique and the factor analysis technique. The results of the research obtained from the factor analysis test showed that there were 3 factors that had the most dominant influence on customer satisfaction in choosing public transportation services, the Budiman bus majoring in Tasikmalaya-Cikarang. These factors are: travel cost factor 36.59\%, travel time factor $12.86 \%$, security/safety factor $7.422 \%$. The most dominant factors affecting customer satisfaction are travel costs, travel time factors and security/safety factors. while the rest is influenced by other factors not examined.

Keywords: Factor Analysis, Public Transportation Services, Customer Satisfaction.

\section{PENDAHULUAN}

Perkembangan Transportasi saat ini membuat tingkat persaingan antar perusahaan-perusahaan semakin ketat, salah satu Transportasi yang berkembang saat ini adalah Transportasi Darat berupa Bus, Bus sangat diperlukan dan dibutuhkan masyarakat karena Bus merupakan angkutan umum yang banyak diminati masyarakat selain harganya yang terjngkau Bus juga dapat membuat tingkat kemacetan lalu lintas menjadi mereda, karena nya Bus merupakan sarana Transportasi yang sangat berperan penting dalam kehidupan masyarakat.

Akan tetapi dengan keterbatasan alat Transportasi yang ada, membuat masyarakat lebih memilih untuk menggunakan kendaraan pribadi dari pada angkutan umum, menurutnya kendaraan pribadi jauh lebih aman, nyaman dan lebih menghemat waktu. Tanpa mengetahui dampak dari banyaknya jumlah kendaraan tersebut yaitu tingkat kemacetan yang semakin tinggi.

Perusahaan otobus Budiman adalah salah satu Jasa Transportasi Darat yang populer, khususnya untuk masyarakat Jawa Barat. Dengan memberikan pelayanan Transportasi dengan Rute Bus AKAP (antar kota antar propinsi) yang dikelola oleh PT HS.Budiman 45. Perusahaan Budiman ini dulunya didirikan oleh Saleh Budiman di tahun 1992 silam. Untuk letak Kantor Pusatnya saat ini berada di jl. H Juanda no. 31 Tasikmalaya. 
Dengan hadirnya Bus Budiman salah satu nya ada pada lintasan Karawang, diharapkan dapat memenuhi kebutuhan masyarakat dan memberikan kepuasan. menurut fandy Tjiptono (2005:78) dasarnya tujuan dari sebuah Bisnis ialah untuk menciptakan para pelanggan yang puas. Berdasarkan latar belakang diatas, maka penelitian ini bertujuan untuk ,1. Untuk mengetahui, menganalisis dan menjelaskan faktor-faktor yang mempengaruhi kepuasan pelanggan pada Jasa Transportasi perusahaan otobus Budiman Jurusan Tasikmalaya-Cikarang, 2. Untuk mengetahui, menganalisis, dan menjelaskan faktor apa yang paling dominan mempengaruhi kepuasan pelanggan pada jasa Transportasi perusahaan otobus Budiman Jurusan Tasikmalaya-Cikarang.

\section{Pengertian Manajemen}

Menurut Malayu S.P Hasibuan (2011:2) menjelaskan bahwa manajemen merupakan ilmu dan seni yang mengatur tentang proses pemanfaatan sumber daya manusia dan sumber-sumber lainnya secara efektif dan efisien untuk mencapai suatu tujuan tersebut.

\section{Pengertian Manajemen Pemasaran}

Menurut Hery, (2019:3) dalam bukunya manajemen pemasaran menjelaskan bahwa pemasaran berhubungan erat dengan mengidentifikasi dan memenuhi kebutuhan orang-orang dan masyarakat.

\section{Pengertian Jasa}

Menurut kotler dalam Lupiyoadi (2014:7) “ jasa adalah setiap tindakan atau kegiatan yang dapat ditawarkan oleh satu pihak kepada pihal lain, pada dasarnya tidak berwujud dan tidak mengakibatkan perpindahan kepemilikan apapun. Produksi jasa mungkin berkaitan dengan produk fisik atau tidak”.

\section{Kepuasan Pelanggan}

Menurut Kotler dan Keller (2009:138) kepuasan (satisfaction) merupakan perasaan senang atau kecewa seseorang yang tumbuh karena membandingkan kinerja yang telah diapresiasi produk (atau hasil) terhadap harapan mereka. Jika kinerja gagal memenuhi harapan, konsumen akan tidak puas. Jika kinerja sesuai 
dengan harapan, konsumen akan puas. Jika kinerja melebihi harapan, konsumen akan sangat puas atau senang.

\section{Faktor-Faktor Yang Mempengaruhi Kepuasan Pelanggan}

Penulis menggunakan penelitian yang dilakukan oleh $\mathrm{M}$, Nassereddine $\mathrm{H}$. Eskandari dalam jurnal (2017) di Universitas Tarbiat Modares, Teheran, Iran. Jadi menurut penelitian literatur dan metode delphi, kriteria pemilihan jenis transportasi dimana kepuasan pelanggan dipengaruhi oleh 6 faktor yaitu : biaya perjalanan, waktu perjalanan, waktu tunggu, kesesuaian, aksebilitas, dan keamanan.

Menurut (Jala : 2015, Becker et al., 2005). Travel Cost merupakan waktu dan biaya perjalanan yang dikeluarkan oleh individu untuk mengunjungi suatu lokasi mewakili harga untuk mengakses tempat tersebut.

Menurut Angshuman Guin dan Jorge Laval (2013) menjelaskan bahwa waktu perjalanan memberikan informasi untuk mengetahui kondisi arus lalu lintas di jalan raya. Waktu perjalanan dapat diperkirakan dengan diukur secara langsung yang disebut dengan Direct Method atau dengan mengukur variabel lalu lintas seperti kecepatan, hunian dan aliran untuk mengestimasi waktu perjalanan yang disebut dengan indirect method.

Menurut Render dkk, (2009 : 418) waktu tunggu diartikan sebagai orangorang atau barang dalam barisan yang sedang menunggu untuk dilayani.

Menurut Tjiptono (2008 : 25) kesesuaian merupakan sejauh mana karakteristik desain dan operasi memenuhi standar-standar yang telah ditetapkan sebelumnya.

Menurut Tjiptono (2014 : 159) aksesibilitas adalah lokasi yang dilalui atau mudah dijangkau sarana transportasi umum.

Menurut Parasuraman, (2005 :132) "keamanan" adalah keadaan bebas dari bahaya dan resiko". Istilah ini bisa digunakan pada sesuatu yang berhubungan dengan kejahatan, segala bentuk kecelakaan dan lain-lain. 


\section{METODE PENELITIAN}

\section{Jenis Penelitian}

penelitian ini masuk ke dalam jenis penelitian kuantitatif, dimana terdapat satu variabel independen, dan 6 faktor yang dianalisis, yaitu : biaya perjalanan, waktu perjalanan, waktu tunggu, kesesuaian, aksesibilitas dan keamanan.

\section{Waktu dan Tempat Penelitian}

Tempat penelitian

Penelitian ini dilaksanakan di Agen Bus Budiman Jurusan TasikmalayaCikarang cabang Klari-Karawang.

Waktu penelitian

Penelitian ini dilaksanakan enam bulan (6 bulan) dari Maret sampai dengan Agustus.

\section{Populasi dan Sampel}

Menurut sugiyono (2016:80) populasi merupakan wilayah generalisasi yang terdiri atas obyek/subyek yang mempunyai kualitas dan karakteristik tertentu yang ditetapkan oleh peneliti untuk dipelajari dan kemudian ditarik kesimpulannya.

Berdasarkan pengertian populasi tersebut, maka penelitian ini mengambil populasi penumpang bus Budiman jurusan Tasikmalaya-Cikarang yang berjumlah rata-rata 905 perbulan pada tahun 2019.

Teknik yang digunakan pada penelitian ini adalah simple random sampling,dimana anggota sampel dari populasi dilakukan secara acak tanpa memperhatikan strata yang ada dalam populasi itu. (Sugiyono (2016:217).

Kriteria yang akan diteliti pada penelitian ini adalah pelanggan Bus Budiman Jurusan Tasikmalaya-Cikarang, yang berada di Agen Bus Budiman Cabang Klari dengan sampel sebanyak 277 responden dengan menggunakan rumus slovin.

\section{Teknik Pengumpulan Data}


Pada penelitian ini menggunakan teknik pengumpulan data kuesioner (angket). Untuk mendapatkan informasi tentang fenomena dan masalah-masalah yang ada di lapangan.

\section{Teknik Analisis Data}

Yang dimaksud dengan analisis data adalah untuk menguji faktor-faktor apa saja yang berpengaruh terhadap kepuasan pelanggan pada Jasa Transportasi Bus Budiman Jurusan Tasikmalaya-Cikarang. Penelitian ini menggunakan teknik analisis deskriptif dan analisis faktor.

\section{Uji Validitas}

Validitas adalah ketepatan atau kecermatan suatu instrumen dalam pengukuran.

\section{Uji Reliabilitas}

Dengan menggunakan alat bantu SPSS 16.0, peneliti dapat mengetahui bahwa kuisioner reliable jila $\mathrm{r}>0,6$ dan tidak reliable jika $\mathrm{r}<0,6$.

\section{Uji Normalitas}

Uji Normalitas adalah sebuah uji yang dilakukan dengan tujuan untuk menilai sebaran data pada sebuah kelompok atau data variabel, apakah data tersebut berdistribusi normal atau tidak. data yang baik merupakan data yang berdistribusi normal dengan ketentuan jika variabel $\alpha$ hitung $>0,05$ maka variabel tersebut berdistribusi normal.

\section{Analisis Faktor}

Agar dapat mengetahui faktor apa saja yang dapat mempengaruhi kepuasan pelanggan pada jasa transportasi bus Budiman jurusan TasikmalayaCikarang, maka perlu digunakan metode analisis faktor. analisis faktor digunakan untuk mereduksi data atau meringkas, dari variabel lama yang banyak diubah menjadi sedikit variabel baru yang disebut faktor, dan masih memuat sebagian besar informasi yang terkandung dalam variabel asli. (Supranto, 2004).

\section{HASIL DAN PEMBAHASAN}

\section{Hasil Penelitian}

\section{Uji Validitas}


Berdasarkan hasil uji validitas mengenai variabel kepuasan pelanggan, seluruh indikator dinyatakan valid karena memiliki nilai Corrected item Total Correlation $(r$ Hitung $) \geq 0,3$.

\section{Uji Reliabilitas}

\section{Tabel 1.1}

\section{Hasil Uji Reliabilitas}

\begin{tabular}{cccc}
\hline Variabel & $\boldsymbol{r}$ Hitung & $\boldsymbol{r}$ Tabel & Kriteria \\
\hline Kepuasan Pelanggan & 0,897 & 0,600 & Reliabel \\
\hline
\end{tabular}

Sumber : Data Primer dianalisis, 2020.

Tabel diatas, dapat diketahui bahwa $r$ Hitung $>r$ Tabel. $r$ Hitung pada variabel kepuasan pelanggan adalah 0,897, maka variabel dinyatakan reliabel karena memiliki $r$ Tabel lebih dari 0,600.

\section{Uji Normalitas}

\section{Tabel 1.2}

Hasil Uji Normalitas

\begin{tabular}{cccc}
\hline Variabel & $\boldsymbol{\alpha}$ Hitung & $\boldsymbol{\alpha}$ Tabel & Kriteria \\
\hline Kepuasan Pelanggan & 0,718 & 0,050 & Valid \\
\hline Sumber : Data Primer dianalisis, 2020. & &
\end{tabular}

Berdasarkan tabel 4.7 diatas, menunjukkan bahwa semua variabel data normal, karena $\alpha$ Hitung semua variabel lebih dari 0,05 .

\section{Hasil Analisis Faktor}

Tabel 1.4

Menamai Faktor

\begin{tabular}{cclcc} 
Faktor & $\begin{array}{c}\text { Nama } \\
\text { Komponen } \\
\text { Faktor Utama }\end{array}$ & \multicolumn{1}{c}{ Indikator } & $\begin{array}{c}\text { Nilai } \\
\text { Faktor }\end{array}$ & $\begin{array}{c}\text { \% Of } \\
\text { Variance }\end{array}$ \\
\hline $\mathbf{1}$ & Faktor 1 & $\begin{array}{l}\text { Tarif sesuai dengan } \\
\text { perjalanan }\end{array}$ & 0,758 & \\
& & $\begin{array}{l}\text { Waktu perjalanan } \\
\text { menyenangkan }\end{array}$ & 0,739 & $36,596 \%$ \\
& $\begin{array}{l}\text { Waktu tunggu bus } \\
\text { sesuai dengan jadwal } \\
\text { keberangkatan } \\
\text { Kemudahan melakukan }\end{array}$ & 0,717 & \\
& & 0,693 &
\end{tabular}




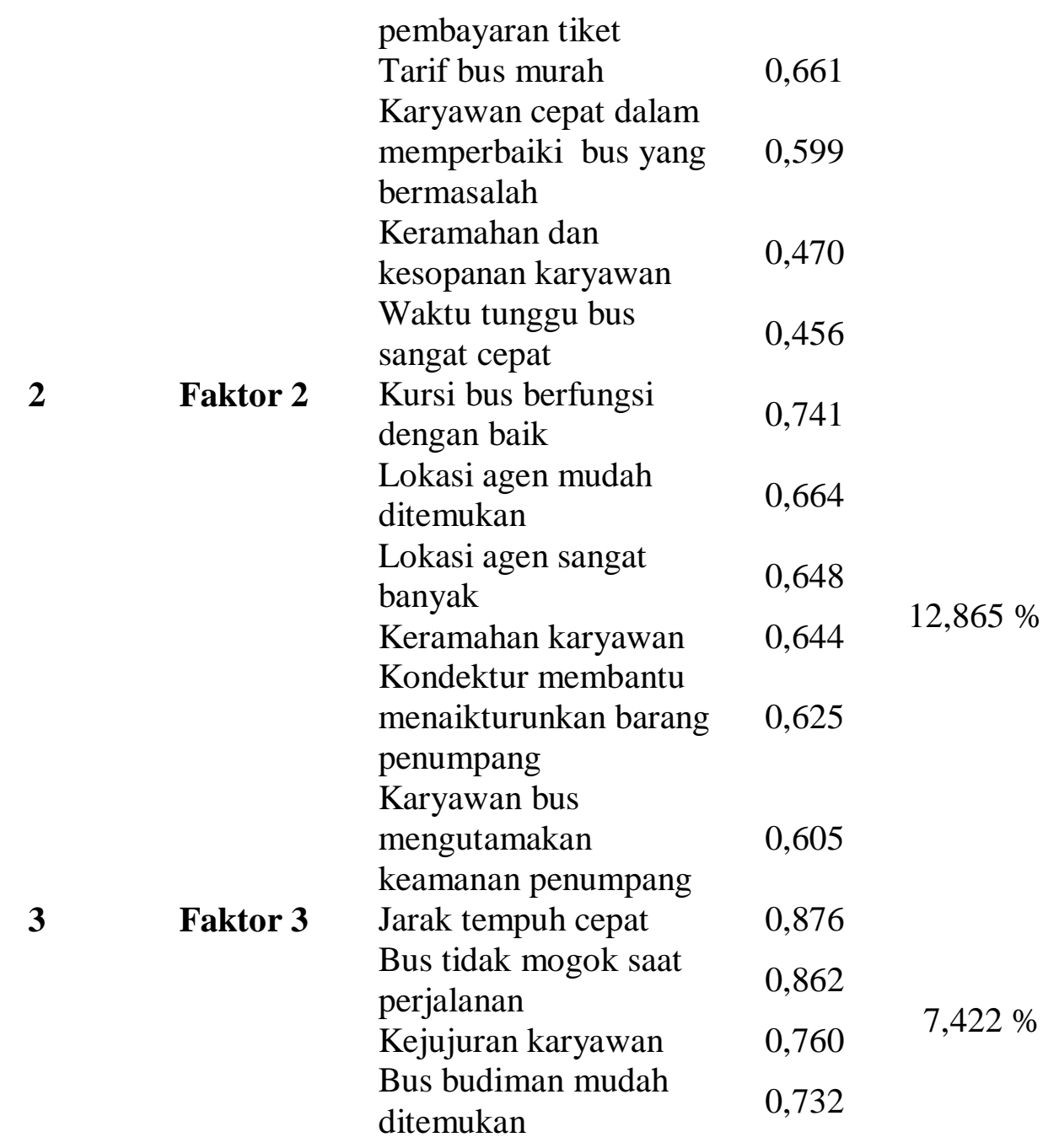

Sumber : Data Primer dianalisis, 2020

Berdasarkan nilai factor loading pada ketiga faktor yang terbentuk, dapat dilihat dengan indikator pembentuknya dengan nilai tertinggi :

a) Faktor 1 Berdasarkan Tarif sesuai dengan perjalanan

b) Faktor 2 Berdasarkan Kursi bus berfungsi dengan baik

c) Faktor 3 Berdasarkan Jarak tempuh cepat

Dari tiga faktor inilah yang paling dominan dan mempengaruhi kepuasan pelanggan pada jasa transportasi bus budiman jurusan Tasikmalaya-Cikarang.

\section{Pembahasan}


Definisi menurut M Nassereddine H Eskandari (2017 : 434) dalam penelitiannya, kepuasan pelanggan sangat dipengaruhi oleh beberapa faktor, yaitu : biaya perjalanan, waktu perjalanan, waktu tunggu, kesesuaian, aksebilitas, dan keamanan.

Faktor yang paling dominan mempengaruhi kepuasan pelanggan pada jasa transportasi otobus budiman jurusan tasikmalaya-cikarang berdasarkan nilai factor loading tertinggi adalah :

Faktor 1 adalah waktu perjalanan dengan indikator jarak tempuh cepat dengan nilai factor loading $(0,876)$. Hasil Faktor waktu perjalanan ini mendukung penelitian terdahulu dari Dede Apriyadi dengan judul Analisis "pengaruh ketepatan waktu, fasilitas dan harga terhadap kepuasan penumpang kereta api di statiun purwosari" bahwa waktu/ketepatan waktu terdapat pengaruh positif dan signifikan terhadap kepuasan penumpang kereta api Bengawan di stasiun Purwosari.

Faktor 2 adalah biaya perjalanan dengan indikator tarif sesuai dengan perjalanan dengan nilai factor loading $(0,758)$, Hasil faktor biaya perjalanan ini mendukung penelitian terdahulu dari Pigi Nurbila Fakultas Ekonomi dan Bisnis, Institut Agman Islam Negeri (IAIN) Bengkulu. dengan judul "Pengaruh kualitas pelayanan, kualitas produk, emosi, harga dan biaya terhadap kepuasan nasabah“ bahwa biaya berpengaruh positif terhadap kepuasan nasabah/konsumen di BNI Syariah Cabang Panorama, Bengkulu”. Faktor biaya turut mempengaruhi kepuasan konsumen.

Faktor 3 adalah keamanan dengan indikator kursi bus berfungsi dengan baik dengan nilai factor loading (0,741), Hasil faktor keamanan ini mendukung penelitian terdahulu dari Fanny Wiryaman Universitas Muhammadiyah Surakarta dengan judul "Faktor-Faktor yang mempengaruhi kepuasan konsumen Taksi Online (Go-Car) di Kota Surakarta" penelitian ini menggunakan variabel keamanan, kenyamanan dan harga. berdasarkan hasil uji t hitung 4,827 dengan nilai signifikansi 0,000 yang menunjukkan bahwa keamanan berpengaruh terhadap kepuasan konsumen. 


\section{KESIMPULAN DAN IMPLIKASI}

\section{Kesimpulan}

Telah terbentuk tiga component yang selanjutnya diberi nama faktor terbentuk, berdasarkan nilai factor loading tertinggi adalah sebagai berikut :

Faktor 1 waktu perjalanan dengan indikator jarak tempuh cepat $(0,876)$

Faktor 2 biaya perjalanan dengan indikator tarif sesuai dengan perjalanan $(0,758)$

Faktor 3 keamanan dengan indikator kursi bus berfungsi dengan baik $(0,741)$.

Faktor yang paling dominan dalam kepuasan pelanggan pada jasa transportasi bus budiman jurusan Tasikmalaya-Cikarang adalah waktu perjalanan, biaya perjalanan dan keamanan.

\section{Implikasi}

\section{Bagi Lembaga atau Perusahaan}

1. Menambah jumlah armada dengan fasilitas dan pelayanan yang baik sehingga pelanggan/konsumen merasa yakin dan puas terhadap apa yang diberikan oleh perusahaan, dengan tetap mengutamakan keselamatan dan kepuasan penumpang, dengan begitu perusahaan dapat bersaing dengan baik dibandingkan dengan perusahaan jasa lainnya.

2. Meningkatkan kembali faktor-faktor yang dianggap lemah yang dapat mempengaruhi kepuasan pelanggan, sehingga konsumen/pelanggan dapat memutuskan kembali untuk tetap menggunakan jasa layanan trasnportasi otobus budiman.

\section{Bagi Penelitian Selanjutnya}

1. Diharapkan bagi peneliti selanjutnya dapat menggunakan metode kualitatif agar bisa mendapatkan data yang lebih rinci dan valid.

2. Diharapkan dapat menambah variabel-variabel lainnya agar penelitian dan pembahasan dapat lebih luas dan beragam.

3. Diharapkan dapat melakukan penelitian yang lebih baik lagi, agar dapat bermanfaat bagi perusahaan maupun peneliti. 


\section{DAFTAR PUSTAKA}

Alma, Buchari. 2011 Manajemen pemasaran jasa. Bandung : Alfabeta

Hery. 2019 manajemen pemasaran. Jakarta : Grasindo

Hardiansyah, H. 2019 manajemen strategis sektor publik. Yogyakarta : Gava

Media

Hasibuan, Malayu . 2011 manajemen dasar, pengertian, dan masalah . Edisi Revisi. Jakarta : Bumi Aksara

Kotler, Philip 2011 manajemen pemasaran. Jakarta : Salemba Empat

Sugiyono, 2016. Metode Penelitian Kuantitatif, Kualitatif, dan R\&D. Bandung : Alfabeta

Sugiyono, 2016. Metode Penelitian Kuantitatif, Kualitatif, dan R\&D. Bandung : Alfabeta

\section{Sumber Skripsi}

ANDRIANI, RATNA. 2019, “Analisis Faktor-Faktor Kepuasan Konsumen Pada Butik Marcella Muslim Galery, Nagasari-Karawang”. Skripsi. Program Studi Manajemen Fakultas Ekonomi dan Bisnis Universitas Singaperbangsa Karawang.

HAERUNISA, 2019. “Analisis Faktor-Faktor yang Mempengaruhi Keputusan Pembelian Konsumen (Pada AlfaMart Pasar Kosambi Karawang)”. Skripsi. Program Studi Manajemen Fakultas Ekonomi dan Bisnis Universitas Singaperbangsa Karawang.

SUMARNA, NANA. 2019. “Analisis Faktor-Faktor yang Mempengaruhi Keputusan Konsumen Untuk Menggunakan Moda Transportasi Kereta Api Lokal (Studi Kasus Pada Pengguna Kereta Api di Stasiun Cikampek)”. Skripsi. Program Studi Manajemen Fakultas Ekonomi Universitas Singaperbangsa Karawang. 


\section{Sumber Jurnal}

Dede Apriyadi. 2017. "Analisis pengaruh ketepatan waktu, fasilitas dan harga terhadap kepuasan penumpang kereta api bengawan di stasiun purwosari” www.ristekdikti.go.id (19 februari 202113.45 )

Fanny Wiryaman. 2019. "Faktor-Faktor yang Mempengaruhi Kepuasan konsumen Taksi Online (Go-Car) di Surakarta" www.eprint.ums.ac.id (19 Februari 2021 13.40)

Figi Nurbila. 2019. "pengaruh kualitas pelayanan, kualitas produk, emosi, harga dan biaya terhadap kepuasan nasabah" www.repository.iainbengkulu.ac.id ( 15 Februari 2021, 15.00)

M. Nassereddine H. Eskandari. 2017. "An Integrated MCDM Approach to Evaluate Public Transportation System in Teheran". Depatement of Industrial Management, Tarbiat Modares, Iran. www.elsevier.com/locate/tra.pdf (14 Februari 2020, 10:28)

\section{Sumber Internet}

https://ebustiket.org diakses pada 11 maret 2020 pukul 09.30 wib https://infotransportasi.com, Priangan Bus Lovers Group Public 2016. Diakses pada 10 juni 2020 pukul 20.40 wib Kompas.com diakses pada 18 mei 2020 Suara.com/NikolausTolen diakses pada 08 maret 2020 pukul 13.45 wib www.mobilkomersial.com diakses pada 10 juni 2020 pukul 20.45 wib 